Check for updates

Cite this: RSC Adv., 2017, 7, 19162

\title{
Matrix isolation study of the early intermediates in the ozonolysis of selected vinyl ethers $\uparrow$
}

\author{
Chen Lv, Lin Du, (D) * Shanshan Tang, Narcisse T. Tsona, (D) Shijie Liu, Hailiang Zhao \\ and Wenxing Wang
}

The matrix isolation technique combined with infrared spectroscopy has been used to characterize Criegee Intermediates $(\mathrm{Cl})$ and other products formed during the ozonolysis reactions of ethyl vinyl ether and $n$ butyl vinyl ether. Twin jet deposition at $14 \mathrm{~K}$ led to a number of new bands indicating the formation of products, with an intensity increase of $\sim 150 \%$ to $400 \%$ when annealing to $30 \mathrm{~K}$. All the infrared absorptions could be assigned to different bands, which provided direct evidence for the formation of primary ozonides, $\mathrm{Cl}$ and secondary ozonides in the systems investigated. Theoretical calculations at the B3LYP-D3/aug-cc-pVTZ level were carried out to complement the experimental observations. Experimental and theoretical results demonstrate that the studied ozonolysis reactions predominantly follow the Criegee mechanism. The current results will allow a better assessment of the potential environmental impacts of vinyl ethers.

Received 23rd January 2017

Accepted 24th March 2017

DOI: $10.1039 / \mathrm{c} 7 \mathrm{ra01011g}$

rsc.li/rsc-advances

atoms may also be important in certain locations during certain times of the year. ${ }^{\mathbf{1 3}}$

Some experimental and theoretical studies on the reaction of ozone with selected vinyl ethers have been performed. The rate coefficient of the ozonolysis of ethyl vinyl ether (EVE) measured at ambient temperatures and atmospheric pressure in different chambers, a borosilicate glass chamber and a FEP Teflon chamber, was determined to be $(2.60 \pm 0.42) \times 10^{-16}$ and $(1.54$ $\pm 0.30) \times 10^{-16} \mathrm{~cm}^{3}$ per molecule per s, respectively. ${ }^{\mathbf{1 2 , 1 4}}$ The rate coefficient of the ozonolysis of $n$-butyl vinyl ether ( $n$-BVE), conducted in a borosilicate glass chamber at similar conditions to the above, was determined to be $(2.59 \pm 0.52) \times 10^{-16} \mathrm{~cm}^{3}$ per molecule per s. ${ }^{12}$ Studies on the ozonolysis of methyl vinyl ether and propyl vinyl ether showed that the main intermediate products in these reactions were formaldehyde and esters, ${ }^{\mathbf{1 5}, 16}$ and thus the formation of Criegee Intermediates (CI) in the course of the reactions was speculated, in agreement with the results observed in the ozonolysis of EVE and $n$-BVE. ${ }^{11,17}$ However, some of the reaction products were not identified due to limitation of the isolation technique. Moreover, the experimental data were obtained just over a narrow temperature range, $287-298 \mathrm{~K}$, for the EVE ozonolysis and solely at $298 \mathrm{~K}$ for $n$-BVE ozonolysis.

The Criegee mechanism in the ozonolysis of alkenes provides extensive indirect experimental evidence, and is supported by theoretical calculations. ${ }^{\mathbf{1 8 - 2 2}}$ This mechanism involves initial formation of a primary ozonide (POZ) by a 1,3 polar addition across the double bond of the alkene, forming a 1,2,3trioxolane species. ${ }^{23}$ The reaction further leads to decomposition into an aldehyde and the proposed CI, a carbonyl oxide. The CI and the aldehyde may then recombine to form
Environment Research Institute, Shandong University, Shanda South Road 27, 250100 Shandong, China. E-mail: lindu@sdu.edu.cn

$\dagger$ Electronic supplementary information (ESI) available. See DOI: 10.1039/c7ra01011g 
a secondary ozonide (SOZ) or react further to form a range of products. ${ }^{24}$ According to the Criegee mechanism, the general equations for the initial reaction steps of ozone with EVE and $n$ BVE are as follows:

$$
\begin{aligned}
\mathrm{O}_{3}+\mathrm{C}_{2} \mathrm{H}_{5} \mathrm{OCH}= & \mathrm{CH}_{2} \rightarrow \alpha\left(\mathrm{C}_{2} \mathrm{H}_{5} \mathrm{OCHOO}+\mathrm{HCHO}\right) \\
& +(1-\alpha)\left(\mathrm{C}_{2} \mathrm{H}_{5} \mathrm{OC}(\mathrm{O}) \mathrm{H}+\mathrm{HCHOO}\right)
\end{aligned}
$$

$\begin{aligned} \mathrm{O}_{3}+ & \mathrm{CH}_{3}\left(\mathrm{CH}_{2}\right)_{3} \mathrm{OCH}=\mathrm{CH}_{2} \rightarrow \alpha\left(\mathrm{CH}_{3} \mathrm{CH}_{2} \mathrm{CH}_{2} \mathrm{CH}_{2} \mathrm{OCHO}\right. \\ & \left.+\mathrm{CH}_{2} \mathrm{OO}\right)+(1-\alpha)\left(\mathrm{CH}_{3} \mathrm{CH}_{2} \mathrm{CH}_{2} \mathrm{CH}_{2} \mathrm{OCHOO}+\mathrm{HCHO}\right)\end{aligned}$

where $\alpha$ represents the proportion of the CI formed.

The matrix isolation technique is an effective method to detect unstable reactive intermediates. It has been successfully used to isolate many novel short-lived species and has the potential to be an effective tool for the stabilization of initial intermediates in the ozonolysis of ethers. Ozone and nine different olefins were deposited separately onto a cold (88 K) window, and after the window was warmed (98 to $423 \mathrm{~K}$ ), two products were formed, presumably a $\pi$-complex and 1,2,3-trioxolane (1,2,3-trioxolane only, for $\left.\mathrm{C}_{2} \mathrm{H}_{4}\right){ }^{25}$ Further warming the window led to the $\pi$-complex decomposition, probably to the initial reactants, while $\mathrm{POZ}$ gave $\mathrm{SOZ}$ and other products. The ozone and ethylene mixtures condensed on a CsI window at 50 $\mathrm{K}$ reacted upon diffusion at approximately $80 \mathrm{~K}$ in solid xenon to form $\mathrm{POZ}$ and $\mathrm{SOZ}$ products, and strong infrared absorptions were observed. ${ }^{26}$ The ethylene $\mathrm{POZ}$ fundamentals were also characterized using ${ }^{13} \mathrm{C},{ }^{18} \mathrm{O}$, and deuterium isotopic data. $\mathrm{POZ}$ and $\mathrm{SOZ}$ were reported from the codeposition of ozone and three different olefins (propylene, 2-trans-butene and methylpropene) in a xenon matrix at $80-110 \mathrm{~K}$ and $\mathrm{a}_{3} \mathrm{Cl}$ solution at 130-150 K. ${ }^{27}$ The codeposition onto a $14 \mathrm{~K}$ window of ozone with 1,2-dibromoethene and 1,2-dichloroethene in argon matrices has been examined using FTIR and it was believed to follow the Criegee pathway. ${ }^{28}$ Using matrix isolation, infrared spectroscopy, and theoretical calculations, the reaction between 1,4-cyclohexadiene and ozone was investigated and besides the widely-known Criegee mechanism, a new pathway to this reaction was found to lead to the formation of the benzene- $\mathrm{H}_{2} \mathrm{O}_{3}$ complex through dehydrogenation. ${ }^{29}$

In this study, matrix isolation technique combined with FTIR spectroscopy was used to identify and characterize early intermediate products in the reactions of ozone with EVE and $n$ BVE in argon matrices. Density functional theory (DFT) calculations were carried out to determine the structures of the reaction intermediate products, the relative energies of different reaction channels and to complement the experiments in assigning the products bands. Most likely reaction mechanisms for these ozonolysis reactions are proposed, and their atmospheric implications are discussed.

\section{Material and methods}

\subsection{Chemicals}

Ethyl vinyl ether $(98 \%$, Aladdin) and $n$-butyl vinyl ether (analytical standard, Aladdin) were used directly as received. $\mathrm{O}_{3}$ was produced by Tesla coil discharge of $\mathrm{O}_{2}(99.999 \%$, Deyang special gas company) and trapped at $77 \mathrm{~K}$ to remove residual $\mathrm{O}_{2}$ and trace gases. Argon (99.999\%, Deyang special gas company) was used as the matrix gas in all experiments. The mixtures of argon/sample were prepared into a mixing reservoir, which was a $5 \mathrm{~L}$ stainless steel vessel, and diluted with argon/sample ratio from $100 / 1$ to $200 / 1$.

\subsection{Blank experiments}

Prior to every codeposition experiments, blank experiments were run on each of the parent compounds, including deposition and annealing. These blanks acted as authentic spectra of the pure starting compounds, allowing for clear identification of product bands as well as an internal standard for the extent of the reaction.

\subsection{Ozonolysis experiments}

All the experiments were performed on a matrix isolation apparatus, using a closed-cycle helium compressor cooled cryostat (PT-SHI-4-5, Janis Research Company, USA) to achieve low temperatures. The cryostat was housed in a vacuum chamber. A pressure gauge (WRG-NW25, Edward, UK) was used to monitor the pressure inside the cryostat chamber. A base pressure of $10^{-5}$ mbar was generally recorded at the beginning of an experiment. The vacuum vessel was equipped with diamond windows throughout, and sat in the sample beam of a FTIR spectrometer (Vertex 80v, Bruker) for the duration of the experiment.

Twin jet mode was used in the depositing process, in which the $\mathrm{Ar} / \mathrm{O}_{3}$ and $\mathrm{Ar} / \mathrm{samples}$ gas mixtures were fed to the cold window through separate ports in the cold head. A temperature programmed method was used to control reaction time. The two gas samples were deposited from separate jets onto the $14 \mathrm{~K}$ cold window at the rate of $2 \mathrm{mmol} \mathrm{h}^{-1}$, allowing for only a very brief mixing time prior to matrix deposition. The matrices were subsequently warmed to 25,30 and then to $35 \mathrm{~K}$ to permit limited diffusion and/or reaction. These matrices were then recooled to $14 \mathrm{~K}$ and additional spectra were recorded. The spectra were recorded from 500 to $5000 \mathrm{~cm}^{-1}$ averaging 128 scans at a resolution of $0.5 \mathrm{~cm}^{-1}$. The data were analyzed with OPUS 7.2 software. The experiment of argon/sample with a ratio of 200/1 was repeated three times to ensure the results were reproducible. An additional experiment with argon/sample ratio of 100/1 was also conducted.

\subsection{Computational methods}

Theoretical calculations were carried out on possible intermediates using Gaussian 09 (Revision E.01). ${ }^{30}$ DFT calculations based on the B3LYP-D3 functional, which includes the dispersion correction, ${ }^{31}$ were used to locate energy minima, determine structures, and calculate vibrational spectra of all relevant intermediates. The geometry optimizations and vibrational frequency calculations were performed using the aug-cc-pVTZ basis set. ${ }^{32}$ The relative reaction energies were calculated by subtracting the sum of electronic and zero-point energies of the reactants from those of the products. 


\section{Results and discussion}

\subsection{Optimized structures and reaction energies}

The immediate products of the reactions of ozone with EVE and $n$-BVE are believed to be the initial intermediates of POZ, CIs and SOZ. Since the POZ formed in these systems are unsymmetrical, cleavage in the second step of the reaction could lead to two different CIs for the ozonolysis of EVE and $n$-BVE. The structures of the POZ, CIs and SOZ in the ozonolysis of EVE and $n$-BVE are shown in Fig. 1 and $\mathrm{S} 1, \uparrow$ respectively. The calculated energies relative to the reactants are given in the parentheses. The relative energy values for POZs were calculated to be -50.3 and $-60.8 \mathrm{kcal} \mathrm{mol}^{-1}$ for the EVE and $n$-BVE ozonolysis reactions, respectively, which indicates that the formation of POZs is energetically favorable.

For the EVE ozonolysis reaction, the relative energies of CIs from channels I and II were calculated to be -75.1 and -65.3 kcal $\mathrm{mol}^{-1}$, respectively. The relative energy of SOZ was determined to be $-105.8 \mathrm{kcal} \mathrm{mol}^{-1}$, which is much lower than the energies of the two CIs. This low energy shows that $\mathrm{SOZ}$ is more stable than the CIs and, therefore, could be detected more easily. It was reported using the $\operatorname{CCSD}(\mathrm{T}) / 6$ $31 \mathrm{G}(\mathrm{d})$ method that the energy barrier for the formation of $\mathrm{CI}$ in channel I is $14.7 \mathrm{kcal} \mathrm{mol}^{-1}$ and the exothermicity value is $0.1 \mathrm{kcal} \mathrm{mol}^{-1} \cdot{ }^{33}$ The dissociation process of channel II, endothermic by $4.8 \mathrm{kcal} \mathrm{mol}^{-1}$, had an energy barrier of $19.0 \mathrm{kcal} \mathrm{mol}^{-1}$. With a lower energy barrier, channel I is likely the dominant reaction pathway. A similar trend was also found in a previous study, ${ }^{11}$ where ethyl formate and $\mathrm{CH}_{2} \mathrm{OO}$ were the main intermediates. The formation energies of the CIs from $n$-BVE ozonolysis were -82.6 and $-72.9 \mathrm{kcal} \mathrm{mol}^{-1}$ for channels I and II, respectively. The formation of butyl formate and $\mathrm{CH}_{2} \mathrm{OO}$ (channel I) was more favorable than the formation of formaldehyde and $\mathrm{CH}_{3}\left(\mathrm{CH}_{2}\right)_{3} \mathrm{OCH}_{2} \mathrm{OO}$ (channel II). Han et $a{ }^{17}{ }^{17}$ also calculated the energy barriers towards the formation of CIs in $n$-BVE ozonolysis and obtained 14.5 and $19.0 \mathrm{kcal} \mathrm{mol}{ }^{-1}$ for channels I and II, respectively. Their results indicate that channel $I$ is more favorable than channel II.

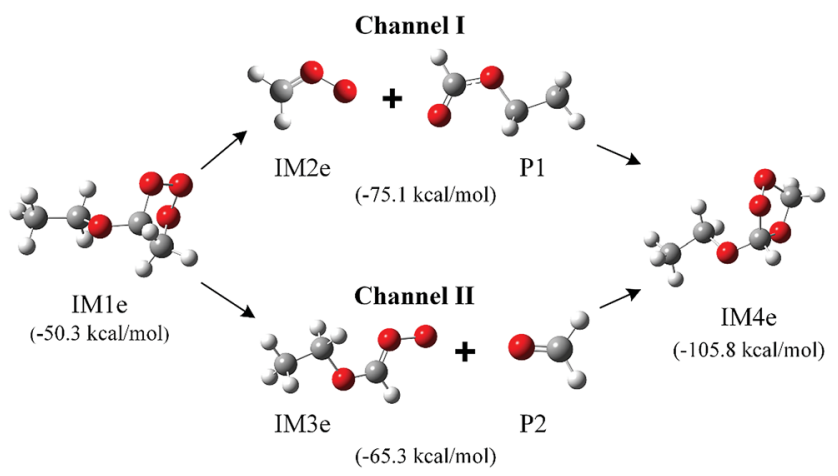

Fig. 1 Calculated structures at the B3LYP-D3/aug-cc-pVTZ level for early intermediates in the ozonolysis of EVE. The calculated energy relative to the reactants was corrected by zero-point vibrational energy (ZPVE) and given in parentheses.

\subsection{Reaction mechanism and spectra}

3.2.1. Ozone + EVE reaction. Twin jet deposition allows for only a very brief mixing time on the condensing matrix surface, at temperatures below room temperature but above the $14 \mathrm{~K}$ temperature of the matrix. In the twin jet experiment, a sample of $\mathrm{Ar} / \mathrm{ozone}=200$ was codeposited with a sample of $\mathrm{Ar} / \mathrm{EVE}=$ 200. Many new bands were observed in the spectrum of this initially deposited matrix, as shown in Fig. 2. The indicated codeposition of EVE and ozone into argon matrices led to a very rapid reaction, and the formation of a number of distinct, medium-to-weak product bands, occurred during a very brief time of matrix condensation. When the matrix was annealed to $25 \mathrm{~K}$ and then re-cooled, some of the initial product bands grew slightly, by a factor of $\sim 1.5$, while others decreased. Then, the matrix was annealed to $30 \mathrm{~K}$ and re-cooled to $14 \mathrm{~K}$. The initial product bands grew considerably at $30 \mathrm{~K}$ (Fig. 2), by factors between $\sim 1.5$ and 4 (150\% to $400 \%$ increase compared to $14 \mathrm{~K}$ ). These observations imply that the energy barrier in the reaction of ozone with EVE might be very low. Also, the large number of product bands suggests that more than one product was formed under the matrix condition. The new product bands and their assignments are summarized in Table 1.

An additional twin jet experiment was conducted by changing the argon/EVE ratio to 100, while the argon/ozone ratio was held constant. The experiment was conducted to provide some variations in the concentration, while maintaining relatively concentrated conditions to increase the likelihood of secondary reactions. The same product bands described above were observed, and the observed band intensities varied directly with the concentrations used in the experiment. The infrared spectra at different concentrations are shown in Fig. S2.†

Some studies on the reaction of EVE with $\mathrm{O}_{3}$ have documented the formation of $\mathrm{POZ}$ and $\mathrm{SOZ}$ arising from the Ozonolysis of the $\mathrm{C}=\mathrm{C}$ double bonds. ${ }^{11,33}$ The products of this reaction suggest that the Criegee mechanism may be taking place in this system, although the two CIs have not been observed. The possible pathway generating POZ and CI was consistent with the known, low activation barrier $(\sim 2.5 \mathrm{kcal}$ $\mathrm{mol}^{-1}$ ) pathway for the reaction of ozone with EVE. ${ }^{33}$ This reaction was believed to lead initially to the POZ, with an exothermicity on the order of $51 \mathrm{kcal} \mathrm{mol}^{-1}$. If the energy was not removed sufficiently, the reaction proceeded through a second barrier leading to decomposition of POZ and formation of CIs. For small alkenes, the barrier separating the POZ from the CI was $\sim 18 \mathrm{kcal} \mathrm{mol}^{-1}$, substantially less than the exothermicity of the initial reaction. ${ }^{24}$ The CI could either be stabilized in the matrix or undergo a recombination process to form the SOZ. The most likely step in a subsequent reaction would be decomposition by $\mathrm{CO}_{2}$ elimination from the carbonyl oxide moiety of the $\mathrm{CI}^{24}$ However, this possibility could be eliminated by comparing experimental data to theoretical calculations ${ }^{33}$ and literature spectra. ${ }^{34}$ Further reactions leading to stable final products were not expected to occur within the matrix due to the nature of the physical environment (low temperature) and the known stability of SOZ. 


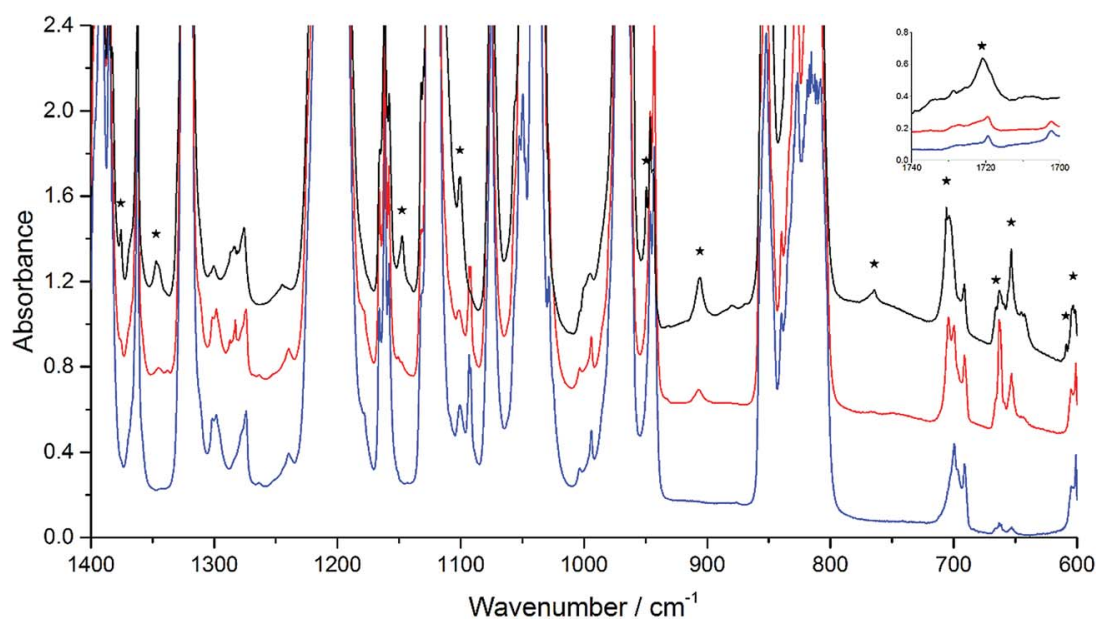

Fig. 2 Infrared spectra of the co-deposition of the samples of $\mathrm{Ar} / \mathrm{EVE}=200$ and $\mathrm{Ar} / \mathrm{O}_{3}=200$. The red line (middle) indicates initial deposition at $14 \mathrm{~K}$ and the black line (top) represents the spectrum after annealing to $30 \mathrm{~K}$, compared to a blank spectrum of Ar/EVE $=200$ (blue, bottom). Bands marked with an asterisk are the product bands.

Table 1 Band positions (in $\mathrm{cm}^{-1}$ ) and assignments for initial intermediates in the thermal reaction of ozone with EVE at $30 \mathrm{~K}$

\begin{tabular}{lll}
\hline $\begin{array}{l}\text { Experimental } \\
\text { bands }\end{array}$ & Calculated bands ${ }^{a}$ & Assignments \\
\hline 653 & 754 & POZ \\
666 & 788 & POZ \\
706 & 812 & Ethyl formate \\
764 & 754 & POZ \\
906 & 906 & POZ \\
949 & 912 & CI \\
959 & 950 & POZ \\
1056 & 1023 & Ethyl formate \\
& 1040 & SOZ \\
& 1064 & POZ \\
& 1077 & SOZ \\
1100 & 1094 & $\mathrm{CI}$ \\
1147 & 1151 & SOZ \\
& 1142 & SOZ \\
& 1170 & SOZ \\
& 1171 & $\mathrm{CI}$ \\
& 1180 & SOZ \\
& 1201 & $\mathrm{CI}$ \\
& 1204 & $\mathrm{CI}$ \\
& 1249 & POZ \\
1347 & 1288 & SOZ \\
1375 & 1399 & SOZ \\
1720 & 1782 & Ethyl formate \\
& &
\end{tabular}

${ }^{a}$ Calculated at the B3LYP-D3/aug-cc-pVTZ level of theory.

While POZ, CI, and SOZ are potential, reasonable intermediate products in the EVE ozonolysis, definitive identification and band assignments are challenging. The assignments could be achieved by comparing the vibrations of functional groups obtained from theoretical calculations to their infrared absorption characteristic peaks (Table 1). A good fit between experiment and theory was best achieved by invoking the presence of all three species (POZ, CI, and SOZ) in the argon matrix. This was in agreement with the observation that the peaks located at 653, 666, 906 and $959 \mathrm{~cm}^{-1}$ grew considerably more than the others did, indicating the presence of multiple species. Due to some bands such as 1040, 1046, 1077, 1142, $1170,1171,1180,1201,1204$ and $1249 \mathrm{~cm}^{-1}$ that were overlapping with parent bands or other product bands, good quantitative intensities could not be obtained for all the product bands. Nonetheless, the bands measured precisely could be reasonably assigned to $\mathrm{POZ}, \mathrm{CI}$ and SOZ in the light of position and growth rate with annealing. Such a set of assignments accounted for nearly all the calculated vibrational bands of these three species with calculated intensities greater than 10 $\mathrm{km} \mathrm{mol}{ }^{-1}$. The only calculated band with $I>10 \mathrm{~km} \mathrm{~mol}^{-1}$ that was not observed was predicted to fall very close to the experimentally observed strong parent bands.

Vibrational modes and assignments of the bands to CIs were particularly diagnosed by comparing some modes from theoretical calculations with similar modes in other similar structures reported in the literature. One such mode for the CI was the $\mathrm{C}=\mathrm{O}$ stretching mode in ethyl formate, observed at 1720 $\mathrm{cm}^{-1}$, which agreed well with the calculated position of 1782 $\mathrm{cm}^{-1}$. The calculated absorption of $\mathrm{C}=\mathrm{O}$ stretching mode in formaldehyde is $1831 \mathrm{~cm}^{-1}$. The absorption of the $\mathrm{POZ}$ in this region was the weak $\mathrm{H}-\mathrm{C}-\mathrm{H}$ scissoring mode, determined to be $1522 \mathrm{~cm}^{-1}$ with low intensity. No vibrational mode for SOZ was expected in this region. Thus, the observation of the product band at $1720 \mathrm{~cm}^{-1}$ would require the presence of a carbonylcontaining species, making the fit to CI reasonable, with the systematic $62 \mathrm{~cm}^{-1}$ overestimation by theoretical calculations. The $\mathrm{C}=\mathrm{O}$ mode in different molecules was observed at 1733 , 1742, 1740 and 1715-1722 $\mathrm{cm}^{-1}$ in cyclopentene, cyclopentadiene, 1,3-cyclohexadiene and ethylene, respectively. ${ }^{24,29,35}$

Some CI bands could be indicated from the great change of the peaks at different temperature. Calculations of bands for two CIs indicated that each had one very intense mode, the $\mathrm{O}-\mathrm{O}$ stretching mode in the $900-1000 \mathrm{~cm}^{-1}$ region. Only one peak at $949 \mathrm{~cm}^{-1}$ was observed in this region. Though not obvious at 14 $\mathrm{K}$, this peak appeared at $25 \mathrm{~K}$ and then, grew significantly as the 
matrix was annealed to $30 \mathrm{~K}$. The peak could be definitively assigned to formaldehyde-O-oxide. Meanwhile, the characteristic intense $\mathrm{O}-\mathrm{O}$ stretching modes of the two possible $\mathrm{CI}$ structures were computed to be $912 \mathrm{~cm}^{-1}$ for formaldehyde- $O$ oxide (IM2e) and $880 \mathrm{~cm}^{-1}$ for $\mathrm{C}_{2} \mathrm{H}_{5} \mathrm{OCHOO}$ (IM3e). The band position of formaldehyde-O-oxide was closer to the experimental peak $\left(949 \mathrm{~cm}^{-1}\right)$ than the peak of $\mathrm{C}_{2} \mathrm{H}_{5} \mathrm{OCHOO}$. The $\mathrm{O}-\mathrm{O}$ stretching mode in gaseous formaldehyde-O-oxide, measured at $298 \mathrm{~K}$ by a step-scan FTIR spectrometer, was located at 908 $\mathrm{cm}^{-1} .^{36}$ The difference between this band position and the 949 $\mathrm{cm}^{-1}$ obtained in the current study is likely assigned to the difference in temperatures between the two experiments, which have different effect on the matrix. Band positions in other systems were also found to change with respect to change in temperature. ${ }^{37}$ Thus, these results support the identification of the $\mathrm{CI}$ and show that channel $\mathrm{I}$ is the dominating path in the ozonolysis of EVE.

The interesting part of the POZ molecule was the $-\mathrm{O}-\mathrm{O}-\mathrm{O}-$ group, and the information on the binding in this group could be obtained through comparison to similar molecules containing the trioxygen linkage. The relative intensities and positions between the two fundamentals for $\mathrm{O}_{3}$ and $\mathrm{O}_{3}{ }^{-}$showed that the weak $906 \mathrm{~cm}^{-1}$ band and the strong $764 \mathrm{~cm}^{-1}$ band were assigned to the symmetric and antisymmetric $\mathrm{O}-\mathrm{O}-\mathrm{O}$ stretching mode, respectively. ${ }^{38,39} \mathrm{~A}$ similar comparison could be made with the spectrum of $\mathrm{CF}_{3}-\mathrm{O}-\mathrm{O}-\mathrm{O}-\mathrm{CF}_{3}$ (ref. 40) and 1,2,3-trioxolan. ${ }^{26}$ The $\mathrm{O}-\mathrm{O}-\mathrm{O}$ modes in different molecules showed that the $\mathrm{O}-\mathrm{O}$ stretching mode of POZ is lower than those in ozone and inorganic ozonides. The $\mathrm{O}-\mathrm{O}-\mathrm{O}$ bonds in $\mathrm{POZ}$ are weak $\sigma$ bonds, particularly relative to the "standard" $\mathrm{O}-\mathrm{O}$ single bond fundamental at $880 \mathrm{~cm}^{-1}$ in hydrogen peroxide. ${ }^{41}$ The ease of POZ to decompose by breaking an $\mathrm{O}-\mathrm{O}$ bond was also indicative of weak $\mathrm{O}-\mathrm{O}$ bonds. From the calculations, the most intense absorption of EVE is the O-O-O antisymmetric stretching vibration, which was measured to be at $754 \mathrm{~cm}^{-1}$.

Recombination of CI and ethyl formate within the matrix environment may lead to the formation of SOZ. Calculations predicted that the very intense band at $1151 \mathrm{~cm}^{-1}$ was the symmetric $\mathrm{H}-\mathrm{C}-\mathrm{H}$ bending vibration of the trioxolane ring. The only candidate in this region was a product band at $1147 \mathrm{~cm}^{-1}$. This band was not observed at $14 \mathrm{~K}$, but it appeared at $25 \mathrm{~K}$ and grew significantly at $30 \mathrm{~K}$. However, the most intense computed band at $1077 \mathrm{~cm}^{-1}$, namely, the antisymmetric C-O-C stretching band of SOZ, was overlapped with other vibrational modes of the parent molecules, and it could not be identified in the experimental spectra.

Besides, the peaks at 653,666 , and $959 \mathrm{~cm}^{-1}$ were attributed to the $-\mathrm{CH}_{2}$ asymmetric bending, $\mathrm{O}-\mathrm{O}-\mathrm{O}$ symmetric bending, and $\mathrm{O}-\mathrm{C}-\mathrm{O}$ asymmetric stretching in $\mathrm{POZ}$, respectively. The peaks at 706 and $1056 \mathrm{~cm}^{-1}$ were assigned to the $-\mathrm{CH}_{2}$ asymmetric bending vibration and $\mathrm{C}-\mathrm{C}-\mathrm{O}$ asymmetric stretching vibration in ethyl formate. The $-\mathrm{CH}_{2}$ wagging vibration in $\mathrm{SOZ}$ was observed at $1375 \mathrm{~cm}^{-1}$, while the $-\mathrm{CH}_{2}$ twisting vibration was at $1347 \mathrm{~cm}^{-1}$. With the help of the calculations, several other weak bands were also tentatively assigned (Table 1).

3.2.2. Ozone $+\boldsymbol{n}$-BVE reaction. To confirm that the ozonolysis of $n$-BVE proceeded through the Criegee mechanism, the reaction of EVE and ozone was used for comparison. In an initial twin jet experiment, a sample of Ar/ozone $=200$ was codeposited with a sample of $\mathrm{Ar} / n-\mathrm{BVE}=200$. A few new product bands such as 635, 784, 933, and $1742 \mathrm{~cm}^{-1}$ were observed in the spectrum of the initially deposited matrix (Fig. 3). When the matrix was annealed, first to $25 \mathrm{~K}$ and then to $30 \mathrm{~K}$ and recooled to $14 \mathrm{~K}$, some bands such as the $653 \mathrm{~cm}^{-1}$ band grew substantially. The product bands are summarized in Table 2. An additional twin jet experiment was conducted with an argon $/ n$-BVE ratio of 100 . The same initial product bands were observed, with band intensities varying directly with the specific value of the concentrations (Fig. S3†). Although some experimental bands at 1021, 1072, 1177, 1189, 1193, and 1199 $\mathrm{cm}^{-1}$ overlapped with the parent bands, calculations predicted their positions. These bands are also listed in Table 2 .

On the basis of the Criegee mechanism and the results for the EVE/ozone system, likely candidates for the bands of initial

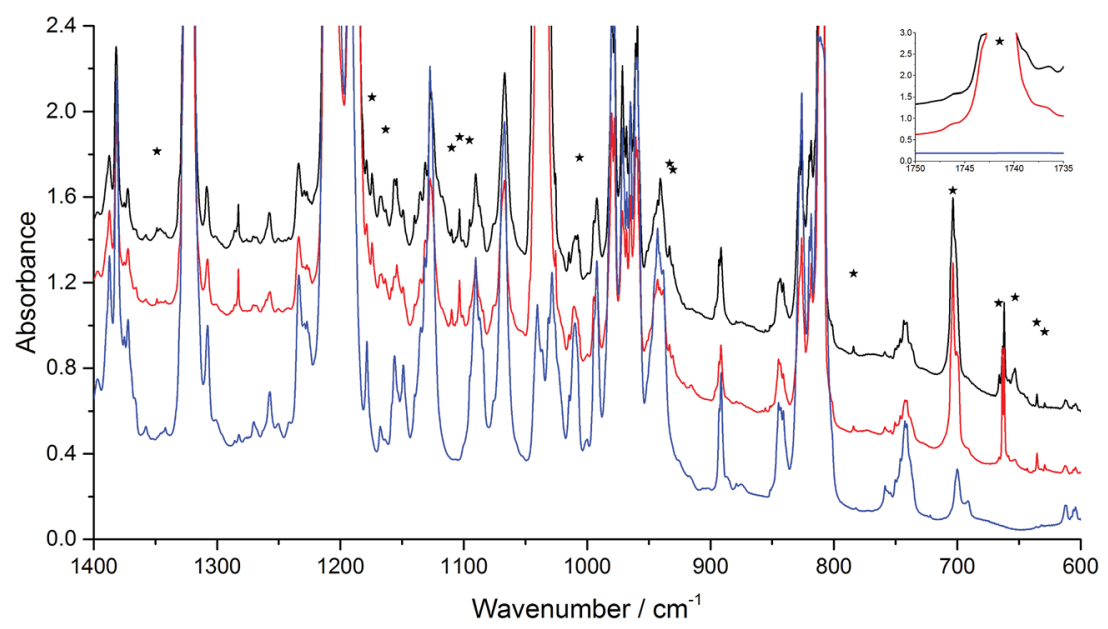

Fig. 3 Infrared spectra of the co-deposition of the samples of $\mathrm{Ar} / \mathrm{n}$-BVE $=200$ and $\mathrm{Ar} / \mathrm{O}_{3}=200$. The red line (middle) indicates initial deposition at $14 \mathrm{~K}$ and the black line (top) represents the spectrum after annealing to $30 \mathrm{~K}$, compared to a blank spectrum of $\mathrm{Ar} / \mathrm{n}$-BVE $=200$ (blue, bottom). Bands marked with an asterisk are the product bands. 
Table 2 Band positions $\left(\mathrm{cm}^{-1}\right)$ and assignments for initial intermediates in the thermal reaction of ozone with $n$-BVE at $30 \mathrm{~K}$

\begin{tabular}{lll}
\hline $\begin{array}{l}\text { Experimental } \\
\text { bands }\end{array}$ & Calculated bands ${ }^{a}$ & Assignments \\
\hline 635 & 640 & CI \\
653 & 660 & SOZ \\
666 & 673 & $\mathrm{CI}$ \\
703 & 694 & $\mathrm{POZ}$ \\
784 & 753 & $\mathrm{POZ}$ \\
930 & 903 & $\mathrm{POZ}$ \\
933 & 912 & $\mathrm{CI}$ \\
1006 & 979 & $\mathrm{POZ}$ \\
& 1021 & $\mathrm{SOZ}$ \\
1103 & 1068 & $\mathrm{CI}$ \\
& 1072 & $\mathrm{POZ}$ \\
1109 & 1080 & $\mathrm{SOZ}$ \\
1154 & 1153 & $\mathrm{SOZ}$ \\
1163 & 1145 & $\mathrm{POZ}$ \\
1174 & 1171 & SOZ \\
1187 & 1205 & $\mathrm{Butyl}$ formate \\
& 1177 & $\mathrm{POZ}$ \\
& 1189 & SOZ \\
& 1193 & POZ \\
& 1199 & SOZ \\
1742 & 1782 & $\mathrm{Butyl}$ formate
\end{tabular}

${ }^{a}$ Calculated at the B3LYP-D3/aug-cc-pVTZ level of theory.

products were POZ, CI, and SOZ from $n$-BVE ozonolysis. Band assignments were made with the comparison to the EVE ozonolysis and with the help of computational results. The band observed at $1742 \mathrm{~cm}^{-1}$ indicated the formation of $\mathrm{C}=\mathrm{O}$ group, which is in agreement with the calculated $\mathrm{C}=\mathrm{O}$ stretching of butyl formate at $1782 \mathrm{~cm}^{-1}$. The $\mathrm{O}-\mathrm{O}$ stretching mode of the CI was observed at $933 \mathrm{~cm}^{-1}$, which grew significantly after annealing to $30 \mathrm{~K}$. The agreement between calculated and observed band positions is very good, though some bands were overlapped by parent absorptions, supporting the formation and stabilization of $\mathrm{CI}$ in the $n$-BVE ozonolysis. Alternative explanations involving products from fragmentation could include 1-butanol formed through $\mathrm{CO}_{2}$ elimination from the CI. However, this possibility can be excluded by comparing the spectrum obtained to authentic argon matrix spectrum of 1butanol available in the literature. ${ }^{\mathbf{2}}$

Table 3 Fundamental vibrations $\left(\mathrm{cm}^{-1}\right)$ for ozone, ozonides, and trioxides

\begin{tabular}{lll}
\hline Molecule & $\begin{array}{l}\text { Antisymmetric O-O-O } \\
\text { stretching }\end{array}$ & $\begin{array}{l}\text { Symmetric O-O-O } \\
\text { stretching }\end{array}$ \\
\hline $\mathrm{O}_{3}{ }^{a}$ & 1040 & 1104 \\
$\mathrm{O}_{3}{ }^{-b}$ & 804 & 1016 \\
$\mathrm{CF}_{3}-\mathrm{O}-\mathrm{O}-\mathrm{O}-\mathrm{CF}_{3}{ }^{c}$ & 773 & 875 \\
$1,2,3-\mathrm{Trioxolan}^{d}$ & 647 & 846 \\
$\mathrm{EVE}-\mathrm{POZ}^{e}$ & 764 & 906 \\
$n-\mathrm{BVE}-\mathrm{POZ}^{e}$ & 784 & 930 \\
${ }^{a}$ ref. 38. $^{b}$ ref. 39. $^{c}$ ref. $^{2}$ & \\
&
\end{tabular}

For the POZ, particularly characteristic and intense bands were observed at 784 and $930 \mathrm{~cm}^{-1}$. The two most intense bands were determined to be the antisymmetric $\mathrm{O}-\mathrm{O}-\mathrm{O}$ stretching mode at $753 \mathrm{~cm}^{-1}$ and the symmetric $\mathrm{O}-\mathrm{O}-\mathrm{O}$ stretching mode at $903 \mathrm{~cm}^{-1}$. Similarly, the $\mathrm{O}-\mathrm{O}$ stretching mode in the ring of POZ were significantly lower than those in ozone ${ }^{38}$ and in inorganic ozonide. ${ }^{39}$ The summary of the vibrations in similar structures are provided in Table 3. The comparison shows that the $\mathrm{O}-\mathrm{O}-\mathrm{O}$ bonds in the $\mathrm{POZ}$ from $n$-BVE ozonolysis are relatively weak $\sigma$ bonds, which may easily be broken and lead to further reactions. This agreement for the two most distinct modes is a strong support to the identification of POZ. In addition, two other peaks were found in the experimental spectrum, the O-O-O symmetric bending vibration at $703 \mathrm{~cm}^{-1}$ and the $\mathrm{C}-\mathrm{C}-\mathrm{C}$ symmetric stretching vibration at $1163 \mathrm{~cm}^{-1}$.

Two intense bands observed at 1109 and $1154 \mathrm{~cm}^{-1}$ were assigned to the SOZ, while the two most intense bands of the SOZ from calculations were obtained at 1080 and $1153 \mathrm{~cm}^{-1}$. These bands support the identification of SOZ in the $n$-BVE ozonolysis reaction. The spectroscopic properties presented in this study support the observation and characterization of $\mathrm{POZ}$, $\mathrm{CI}$ and SOZ in the reaction of ozone with $n$-BVE, hence providing direct evidence for the Criegee mechanism.

\section{Conclusions}

Matrix isolation technique combined with FTIR was used to identify and characterize the direct intermediate products formed during the EVE and $n$-BVE ozonolysis reactions. DFT calculations based on the B3LYP-D3/aug-cc-pVTZ level of theory were performed to determine the most likely structures, spectra, and relative energies of the direct products in these reactions. By combining experimental observations with theoretical calculations, the product bands were successfully assigned to the primary ozonides, Criegee intermediates, and secondary ozonides. Our findings demonstrate that the ozonolysis of EVE and $n$ BVE predominantly follow the Criegee mechanism, and the dominant pathways in these reactions lead to the formation of carbonyl oxides and corresponding esters. The current results further provide significant information to better understand the processes of the atmospheric degradation of vinyl ethers.

\section{Acknowledgements}

This work was supported by National Natural Science Foundation of China (21577080, 91644214, 21407095) and Shandong Provincial Natural Science Foundation, China (ZR2014BQ013).

\section{Notes and references}

1 S. G. Van Ornum, R. M. Champeau and R. Pariza, Chem. Rev., 2006, 106, 2990-3001.

2 H. Singh, Y. Chen, A. Staudt, D. Jacob, D. Blake, B. Heikes and J. Snow, Nature, 2001, 410, 1078-1081.

3 F. Fehsenfeld, J. Calvert, R. Fall, P. Goldan, A. B. Guenther, C. N. Hewitt, B. Lamb, S. Liu, M. Trainer and H. Westberg, Global Biogeochem. Cycles, 1992, 6, 389-430. 
4 A. Mellouki, T. J. Wallington and J. Chen, Chem. Rev., 2015, 115, 3984-4014.

5 A. Mellouki, G. Le Bras and H. Sidebottom, Chem. Rev., 2003, 103, 5077-5096.

6 M. Kalberer, J. Yu, D. R. Cocker, R. C. Flagan and J. H. Seinfeld, Environ. Sci. Technol., 2000, 34, 4894-4901.

7 U. Pöschl, Angew. Chem., Int. Ed., 2005, 44, 7520-7540.

8 M. Scarfogliero, B. Picquet-Varrault, J. Salce, R. DurandJolibois and J.-F. Doussin, J. Phys. Chem. A, 2006, 110, 11074-11081.

9 G. Thiault and A. Mellouki, Atmos. Environ., 2006, 40, 55665573.

10 M. He, H. Wang, X. Sun, Q. Zhang and W. Wang, J. Theor. Comput. Chem., 2009, 8, 261-277.

11 G. Thiault, R. Thévenet, A. Mellouki and G. Le Bras, Phys. Chem. Chem. Phys., 2002, 4, 613-619.

12 S. Zhou, I. Barnes, T. Zhu, I. Bejan and T. Benter, J. Phys. Chem. A, 2006, 110, 7386-7392.

13 L. Wang, M. Ge and W. Wang, Chem. Phys. Lett., 2009, 473, 30-33.

14 E. Grosjean and D. Grosjean, J. Atmos. Chem., 1999, 32, 205232.

15 B. Klotz, I. Barnes and T. Imamura, Phys. Chem. Chem. Phys., 2004, 6, 1725-1734.

16 S. Zhou, I. Barnes, T. Zhu, B. Klotz, M. Albu, I. Bejan and T. Benter, Environ. Sci. Technol., 2006, 40, 5415-5421.

17 D. Han, H. Cao, Y. Sun, R. Sun and M. He, Chemosphere, 2012, 88, 1235-1240.

18 W. T. Chan and I. P. Hamilton, J. Chem. Phys., 2003, 118, 1688-1701.

19 M. F. Hendrickx and C. Vinckier, J. Phys. Chem. A, 2003, 107, 7574-7580.

20 I. Ljubić and A. Sabljić, J. Phys. Chem. A, 2002, 106, 47454757.

21 J. M. Anglada, R. Crehuet and J. M. Bofill, Chem.-Eur. J., 1999, 5, 1809-1822.

22 L. Vereecken and J. S. Francisco, Chem. Soc. Rev., 2012, 41, 6259-6293.

23 M. Clay and B. S. Ault, J. Phys. Chem. A, 2010, 114, 2799-2805.

24 M. D. Hoops and B. S. Ault, J. Am. Chem. Soc., 2009, 131, 2853-2863.

25 L. A. Hull, I. C. Hisatsune and J. Heicklen, J. Am. Chem. Soc., 1972, 94, 4856-4864.

26 C. K. Kohlmiller and L. Andrews, J. Am. Chem. Soc., 1981, 103, 2578-2583.

27 L. Andrews and C. K. Kohlmiller, J. Phys. Chem., 1982, 86, 4548-4557.
28 R. J. H. Clark and L. J. Foley, J. Phys. Chem. A, 2002, 106, 3356-3364.

29 L. Pinelo, A. D. Gudmundsdottir and B. S. Ault, J. Phys. Chem. $A, 2013$, 117, 4174-4182.

30 M. J. Frisch, G. W. Trucks, H. B. Schlegel, G. E. Scuseria, M. A. Robb, J. R. Cheeseman, G. Scalmani, V. Barone, B. Mennucci, G. A. Petersson, H. Nakatsuji, M. Caricato, X. Li, H. P. Hratchian, A. F. Izmaylov, J. Bloino, G. Zheng, J. L. Sonnenberg, M. Hada, M. Ehara, K. Toyota, R. Fukuda, J. Hasegawa, M. Ishida, T. Nakajima, Y. Honda, O. Kitao, H. Nakai, T. Vreven, J. A. Montgomery Jr, J. E. Peralta, F. Ogliaro, M. J. Bearpark, J. Heyd, E. N. Brothers, K. N. Kudin, V. N. Staroverov, R. Kobayashi, J. Normand, K. Raghavachari, A. P. Rendell, J. C. Burant, S. S. Iyengar, J. Tomasi, M. Cossi, N. Rega, N. J. Millam, M. Klene, J. E. Knox, J. B. Cross, V. Bakken, C. Adamo, J. Jaramillo, R. Gomperts, R. E. Stratmann, O. Yazyev, A. J. Austin, R. Cammi, C. Pomelli, J. W. Ochterski, R. L. Martin, K. Morokuma, V. G. Zakrzewski, G. A. Voth, P. Salvador, J. J. Dannenberg, S. Dapprich, A. D. Daniels, Ö. Farkas, J. B. Foresman, J. V. Ortiz, J. Cioslowski and D. J. Fox, Gaussian 09, Revision E.01, Gaussian, Inc., Wallingford, CT, USA, 2013.

31 S. Grimme, J. Antony, S. Ehrlich and H. Krieg, J. Chem. Phys., 2010, 132, 154104.

32 T. H. Dunning Jr, J. Chem. Phys., 1989, 90, 1007-1023.

33 D. Han, H. Cao, Y. Sun and M. He, Struct. Chem., 2011, 23, 499-514.

34 A. J. Barnes and H. E. Hallam, Trans. Faraday Soc., 1970, 66, 1932-1940.

35 U. Samuni, R. Fraenkel, Y. Haas, R. Fajgar and J. Pola, J. Am. Chem. Soc., 1996, 118, 3687-3693.

36 Y.-T. Su, Y.-H. Huang, H. A. Witek and Y.-P. Lee, Science, 2013, 174-177.

37 A. S. Hansen, L. Du and H. G. Kjaergaard, J. Phys. Chem. Lett., 2014, 5, 4225-4231.

38 L. Andrews and R. C. Spiker Jr, J. Phys. Chem., 1972, 76, 32083213.

39 R. C. Spiker Jr and L. Andrews, J. Chem. Phys., 1973, 59, 18511862.

40 J. D. Witt, J. R. Durig, D. Des Marteau and R. M. Hammaker, Inorg. Chem., 1973, 12, 807-810.

41 R. L. Redington, W. B. Olson and P. C. Cross, J. Chem. Phys., 1962, 36, 1311-1326.

42 M. Kansiz, J. R. Gapes, D. McNaughton, B. Lendl and K. C. Schuster, Anal. Chim. Acta, 2001, 438, 175-186. 